\title{
TRANSMISSÃO PSÍQUICA TRANSGERACIONAL E CONSTRUÇÃO DE SUBJETIVIDADE: RELATO DE UMA PSICOTERAPIA PSICANALIITICA VINCULAR ${ }^{1}$
}

\author{
Isabel Cristina Gomes \\ Sandra Aparecida S.Zanetti
}

Resumo: O presente artigo tem como objetivo refletir acerca do conceito de transmissão psíquica entre gerações, especificamente de uma modalidade - a transmissão psíquica transgeracional - e sua influência na construção das subjetividades individuais e dos vínculos familiares, enfatizando-se aqui o vínculo mãe-filha como gerador de sintomas na criança e conflitos no âmbito familiar, através de um relato clínico de uma psicoterapia psicanalítica vincular, segundo os referenciais de Eiguer (2006) e Berenstein e Puget (1997, 2005). A apresentação do caso clínico permite discutir, ainda, a relação entre a transmissão psíquica transgeracional e o estabelecimento da "maternagem", bem como os resultados obtidos ao longo de todo o processo psicoterápico. A finalidade desse espaço terapêutico familiar é a de propiciar transformações frente ao legado geracional, promovendo o surgimento de uma subjetividade nova, impulsionadora de vida.

Palavras-chave: Transmissão psíquica entre gerações. Subjetividade. Psicoterapia psicanalítica. Vínculo.

\section{Introdução}

O presente artigo tem como objetivo refletir acerca do processo de transmissão psíquica entre gerações, especificamente de uma modalidade - a transmissão psíquica transgeracional - e sua influência na construção das subjetividades individuais e

1 O resumo deste trabalho foi apresentado no Second International Congress for Psychoanalytic Family Therapy, Montreal, agosto de 2006. 
dos vínculos familiares, enfatizando-se aqui o vínculo mãe-filha como gerador de sintomas na criança e conflitos no âmbito familiar, através de um relato clínico de uma psicoterapia psicanalítica vincular.

Freud, ao criar a Psicanálise, deparou-se com um campo de investigações que o levou a teorizar a respeito do aparelho psíquico individual.Todos os seus estudos iniciais basearam-se em estruturas, processos e construções que estivessem relacionadas à constituição subjetiva individual. No entanto, na medida em que evolui em sua teoria, começa a abordar pontos cujos desdobramentos o levaram para além da estrutura psíquica individual, ou seja, para uma intersubjetividade constitutiva (Féres-Carneiro \& Magalhães, 2005).

Em sua obra "Psicologia de Grupo e a Análise do Ego", Freud (1921/1980) irá destacar a presença da intersubjetividade na constituição psíquica do sujeito. Nesse texto, irá afirmar que a construção subjetiva de um indivíduo está invariavelmente envolvida com algo mais, como um modelo, um objeto, um oponente, um auxiliar, de maneira que, desde o princípio das relações mais primitivas da infância, poderíamos dizer que a psicologia individual é também psicologia social. Desde então, o conceito de transmissão psíquica incorporou-se à Psicanálise, contribuindo definitivamente para muitas teorias que trabalham a partir da abordagem grupal, de família e casal.

Baseando-se nesses conceitos formulados por Freud, a Psicanálise pós-freudiana preocupou-se em aprofundar o corpo teórico relacionado à temática dos grupos, considerando a importância de estudar seu processo e suas peculiaridades para a formação subjetiva de um indivíduo. Dentre os autores dessa fase, destacam-se Bion (1970), Pichon-Rivière (1983), Bleger (1972), Kaës (1997) e Eiguer (1998).

Jaroslavsky (2006), em um artigo recente, "El modelo vincular francoargentino contemporáneo", retoma o percurso desses autores, na intenção de sistematizar as diretrizes de uma teoria específica que foi se formulando a partir de tais estudos, em que os conceitos de vínculo e de transmissão da vida psíquica entre gerações são fundamentais para compreender a dinâmica familiar, entendendo a família enquanto um grupo formador da matriz intersubjetiva do nascimento da vida psíquica (Kaës, 1998).

Segundo Kaës (1998), o interesse suscitado pela transmissão da vida psíquica entre gerações testemunha a tentativa, há alguns anos, de elaborar a crise multidimensional que afeta os fundamentos e as modalidades da vida psíquica; a crise na inteligibilidade dos sofrimentos e das organizações patológicas; além das crises nas formas de tratamento e, conseqüentemente, nas condições de conhecimento da própria vida psíquica.

Em todas as dimensões desta crise, a questão da precedência do outro e de mais de um outro - de alguns outros - no destino do indivíduo persiste como uma espécie de desafio à compreensão da vida psíquica a partir dos únicos limites 
daquilo que a determina de maneira interna: a questão do sujeito define-se, cada vez mais necessariamente, no espaço intersubjetivo, e mais precisamente, no espaço e no tempo da geração, do familiar e do grupal, ali onde, exatamente - segundo a formulação de P. Aulagnier - "o Eu pode vir a ser" ou, tem dificuldade de constituir-se. (Kaës, 1998, pp. 5-6)

Dentro desse contexto, portanto, a hipótese sustentada é a de que "o inconsciente de cada indivíduo leva a marca, na sua estrutura e nos seus conteúdos, do inconsciente de um outro, e, mais precisamente, de mais de um outro" (Kaës, 1998, p. 14). Além disso e dessa forma, o material da vida psíquica é algo que se torna passível de ser transmitido, no interior de uma família, entre e inter gerações. Ainda de acordo com esse autor, o que se transmite seria preferencialmente aquilo que não se contém, "aquilo que não se retém, aquilo de que não se lembra: a falta, a doença, a vergonha, o recalcamento, os objetos perdidos, e ainda enlutados" (p.9). O autor enfatiza a noção de algo que é transmitido de um espaço psíquico a outro, sem possibilidade de elaboração, denominando esse mecanismo de transmissão psíquica transgeracional.

Essa modalidade da transmissão psíquica, que é tema dessa reflexão teórico-clínica, envolve a transmissão de um material psíquico que pode não beneficiar a geração seguinte, porque está em "suspensão", num estado em que não há a possibilidade de metabolização e integração de seus conteúdos, no sentido de vir a favorecer o surgimento de transformações criativas ao longo do processo de subjetivação geracional.

Nessas circunstâncias, os conteúdos psíquicos dos filhos estarão marcados pelo funcionamento psíquico dos avós, ou de outros ascendentes, que eles podem não ter conhecido, mas cuja vida psíquica marcou de forma traumática seus próprios pais.... Este tipo de transmissão é considerado alienante e não-estruturante, impedindo a singularização do herdado, pois ela se impõe em estado bruto aos descendentes. (Trachtenberg, Kopittke, Pereira, Chem, \& Mello, 2005, p. 169)

Kaës (2001) considera a identificação como o principal mecanismo envolvido no processo da transmissão psíquica entre gerações. E indica ainda que, nesse processo, não se transmite apenas o negativo, transmitese também "aquilo que ampara e assegura as continuidades narcísicas, a manutenção dos vínculos intersubjetivos, a conservação e complexidade das formas e da vida: ideais, mecanismos de defesa, identificações, certezas, dúvidas" (p.9). Esse tipo de transmissão leva o nome de transmissão psíquica intergeracional e pressupõe um trabalho de ligações e transformações entre as gerações, de acordo com Granjon (2000, p.24). Autores mais recentes, ligados à corrente argentina da Psicanálise Vincular, também se detiveram na mesma definição. 
São aquelas que acontecem entre gerações adjacentes, numa situação de relação direta. Entre as duas gerações está incluído um espaço de metabolização do material psíquico que será transmitido para a geração seguinte, de uma forma transformada e modificada. O herdeiro é um beneficiário dessas mudanças que conduzem a uma diferenciação e a uma evolução entre o que é transmitido e herdado e depois adquirido. (Trachtenberg et al., 2005, p. 168)

Tal trabalho permite que o indivíduo se vincule a um grupo, esse grupo a outro, num encadeamento de gerações: é o que dá a noção de "pertencimento" e o que permite a construção da própria subjetividade, num processo de transformação, de criação, do material que é transmitido.É por esse processo que o indivíduo também se torna, por um lado, autor, e, por outro, proprietário de sua herança. Em última instância, é algo que representa e permeia a história pessoal, familiar e da própria civilização.

Em contrapartida, a transmissão psíquica transgeracional, ainda de acordo com Granjon (2000), é a que possui os aspectos traumáticos, patológicos e sintomáticos de um processo de transmissão bruto, que não possibilita transformações. "O que será, então, transmitido será o traço daquilo que se passou, e não pôde ser pensado, com seu cortejo de terror, vergonha e interditos" (p.25). Aqui encontramos os caracteres de violência, alienação e transmissão do negativo.

Na clínica, defrontamo-nos freqüentemente com a transmissão manifestada no sofrimento dos sujeitos aprisionados em sua incapacidade de metabolizar seus legados. Nossa tarefa, como terapeutas, é reconstituir o percurso simbólico da transmissão e favorecer a elaboração da herança. E é na possibilidade de transformação que investimos recursos terapêuticos, trabalhando para alterar o curso repetitivo do sintoma (Féres-Carneiro \& Magalhães, 2005).

\section{A psicoterapia familiar psicanalítica}

Sob um enfoque histórico, de desenvolvimento e evolução da Psicanálise enquanto teoria e prática clínica, o leque de conhecimentos que a compunha vem cada vez mais se abrindo, desde Freud, com uma Psicanálise voltada para o intrapsíquico. Na continuidade desse pensamento, Winnicott e Bion, entre outros autores, produzem uma complementação desse ponto de vista teórico, expandindo a Psicanálise para a fronteira com o intersubjetivo, na medida em que põem em evidência, no seu corpo teórico, o ambiente externo, a formação e dinâmica de funcionamento dos grupos e o conceito de vínculo.

Esses novos aportes serão amplamente estudados pelos autores da Psicanálise Vincular ou das Configurações Vinculares, que têm, na França, como principais fundadores, Eiguer e Kaës e, na América Latina, PichonRivière, Berenstein e Puget, em que há uma nova ampliação da teoria com a 
inclusão de mais um conceito a ser descrito, o transubjetivo, o qual engloba o mundo sociocultural (Berenstein \& Puget, 1997, p.12), traçando as bases da Psicanálise de família e casal associada à noção de vínculo; diferenciando-se do aparato teórico construído a partir da noção de relação de objeto, oriunda da Psicanálise inglesa, sobre relacionamento amoroso e familiar, que não será objeto de análise nesse artigo. Gomes e Porchat (2006) descrevem toda a trajetória histórica, incluindo as várias correntes de pensamento teórico e técnicas terapêuticas existentes na área de casal e família.

Assim sendo, a terapia familiar psicanalítica, que se baseia nas relações intersubjetivas e nas formações vinculares, tem a oferecer a compreensão e a possibilidade de uma metabolização dos conteúdos psíquicos, que foram transmitidos e que não puderam ser pensados ou representados pela geração descendente. Focando-se nesse tema, Eiguer (2006) entende ser importante que uma terapia familiar psicanalítica deva favorecer a expressão e a comunicação entre seus membros, algo que considera ser muito difícil de se estabelecer naturalmente, e que isso é um processo que "reposa sobre la possibilidad de que las personas se escuchen, que ellas se vuelvan sensibles a lo que el outro siente, a sus dolores y enojos; éste es un paso importante" ${ }^{\prime 2}$ (p.7).E, diante diso, argumenta:

¿Qué función de la familia es más rica que aquella de aprovechar de una intimidad en la cual cada uno reconecerá que es única e permitirá que se restaure el amor de sí tan frecuentemente atropellado por la vida social y profesional? 'Escuchar el dolor' vale mil recomendaciones sobre las condustas a sostener, lo que si embargo privilegian muchas personas: porque escuchar al outro significa implicarse en su vivencia, sentirlo dentro de sí. (Eiguer, 2006, p. 7) $)^{3}$

Corrêa (2000b) também discorre sobre a perspectiva da terapia familiar analítica (TFA) e sua relação com os mecanismos transgeracionais:

As situações clínicas não deixam de evoluir, obrigando-nos constantemente a refletir sobre a especificidade da abordagem grupal familiar, seus objetivos e sua adaptação para as múltiplas situações de crise. De modo geral, a referência aos aspectos transgeracionais nas diversas patologias tem mostrado a importância da presença de toda a família. (p. 49)

A queixa, os conflitos e os dramas apresentados, na situação terapêutica, serão analisados a partir de um contexto grupal. De que família o analista ou psicoterapeuta irá se ocupar? Daquela que é o resultado de

2 "repousa sobre a possibilidade de que as pessoas se escutem, que elas se tornem sensíveis ao que o outro sente, suas dores e desgostos; este é um passo importante".(Tradução nossa).

3 "Que função da família é mais rica que aquela de se aproveitar de uma intimidade na qual cada um reconhecerá que é única e permitirá que se restaure o amor de si tão freqüentemente atropelado pela vida social e profissional? 'Escutar a dor' vale mil recomendações sobre as condutas a sustentar, o que sem dúvida privilegia muitas pessoas: porque escutar o outro significa implicar-se em sua vivência, senti-lo dentro de si" (Tradução nossa). 
"traços" psíquicos inconscientes, constituídos pelos vínculos conjugal, parental, filial ou fraterno e parento-filial da família atual, que, por sua vez, traz referências dos ancestrais.

No presente artigo, abordaremos aspectos relacionados à transgeracionalidade numa terapia familiar psicanalítica focada na formação de um vínculo parento-filial: o de mãe-filha, de acordo com os referenciais de Berenstein e Puget $(1997,2005)$. E, para que se possa melhor compreender esse processo, parece-nos importante delimitarmos, nesse momento, o conceito de vínculo, pois esse difere do conceito de relações de objeto, amplamente utilizado pela Psicanálise de origem inglesa. Tal conceito foi descrito, pela primeira vez, por Pichon-Rivière (1971), da seguinte maneira:

Definimos al vínculo como la estructura compleja que incluye el sujeto, el objeto y su interacción, momentos de comunicación y aprendizaje, configurando un proceso en forma de espiral dialéctica; proceso en cuyo comienzo las imágenes internas y la realidad externa deberían ser coincidientes. (p. 205 ${ }^{4}$

Numa revisão atualizada do termo, Trachtenberg et al. (2005) retomam as definições de Berenstein e Puget $(1993,1997,2004)$, ainda numa tentativa de diferenciar vínculo de relação objetal, enfatizando a presença de três outros espaços psíquicos atrelados ao conceito de vínculo, denominados de intrasubjetivo, intersubjetivo e transubjetivo:

Definem vínculocomouma relaçãoentre doisegos no mínimo,com características de extraterritoriedade da perspectiva do aparelho psíquico, delimitando o espaço intersubjetivo. Na relação vincular, o desejo circula de forma bidirecional, pois ambos os egos são, simultânea e sucessivamente (pacto, acordo), lugar do desejo e da realização do desejo do outro. Já a relação de objeto, entendida como o registro no mundo interno dos objetos parciais ou totais nos quais o ego investe de forma unidirecional, é intraterritorial da perspectiva do aparelho psíquico, delimitando o espaço intrasubjetivo. (Trachtenberg et al, 2005, pp. 171172)

Associando-se o mecanismo de transmissão psíquica ao conceito de vínculo, teremos, então, que as transmissões geracionais são possíveis porque "em todo vínculo intersubjetivo o inconsciente se inscreve e se manifesta" (Kaës, 1998, p. 14). E, diante dessa perspectiva, "muitas vezes", ainda segundo esse autor, "nos vários registros e, em várias linguagens, a psicoterapia familiar psicanalítica tem como objeto específico tratar aquele que está sofrendo com o vínculo de geração" (p. 17). É esse o enfoque que aplicamos na nossa proposta clínica de atendimento familiar vincular. ração, momentos de comunicação e aprendizagem, configurando um processo em forma de espiral dialética; processo em cujo começo as imagens internas e a realidade externa deveriam ser coincidentes" (Tradução nossa). 
No Brasil, existe um fenômeno que, devido às condições precárias de sobrevivência, muitas famílias migram das zonas rurais, para tentar conquistar melhores condições de vida nas grandes cidades, como a capital de São Paulo. Esse artigo irá retratar o atendimento clínico de uma família em que uma menina vivia marcada por "traços psíquicos do que se passou", anterior a ela, e que interferiam na constituição psíquica do feminino, englobando duas gerações antecedentes de mulheres - avó e mãe.

Ambas viveram grande parte da vida no interior, no qual tiveram que executar um serviço árduo (como "bóias-frias") para a sobrevivência de toda a família, o que acarretou a formação de "dinâmicas internas familiares" e de constituições subjetivas que foram transmitidas para a menina, sem que essa tivesse consciência do que estava sendo passado para ela. Tratava-se de um material psíquico alienante, da ordem do negativo, que acabou por gerar sintomas graves nessa criança. Nascida na cidade de São Paulo, capital, e, por isso, não contava sequer com um significado proveniente do ambiente rural contextualizado. Esse fato se articulava com os conteúdos do material psíquico traumático.

$\mathrm{Na}$ apresentação do caso clínico a seguir, refletiremos acerca da problemática da transmissão psíquica transgeracional no estabelecimento da "maternagem", por meio dos resultados obtidos ao longo do processo psicoterápico, e realizaremos uma breve discussão ao final, que levará em consideração as expectativas do terapeuta e as reais possibilidades evolutivas dos pacientes.

\section{Caso clínico}

A queixa inicial, trazida pela mãe ao serviço de triagem de uma clínica-escola, referia-se ao comportamento agressivo de uma menina de 10 anos de idade, que morava em sua companhia e em conjunto com o irmão e padrasto, sendo este irmão, com 5 anos de idade, filho do casamento atual da mãe.

Iniciamos o atendimento com a mãe, que vem acompanhada de seu marido. Nesse início eles nos contaram que a menina, Larissa ${ }^{5}$, estava tendo comportamentos muito agressivos: se ela fosse contrariada, ficava nervosa, pegava uma faca e dizia que ia se matar. Relataram que já havia furado a parede da casa com essa faca, ameaçando se cortar e que na escola ela já havia unhado a professora e a tinha furado com um lápis, porque essa a havia contrariado, e que, além disso, ela também mentia muito.

$\mathrm{Na}$ escola, havia agredido a professora porque essa resolvera colocála de castigo após sua insistência em ficar brincando na classe, durante a aula. Sabrina conta que, apesar de estar sabendo de tudo isso, nunca efetivamente havia visto esse comportamento da filha: sem saber explicar o 
porquê, diz que Larissa nunca havia feito aquilo na frente dela e que, inclusive, por isso tinha resolvido trazer seu marido, que já havia observado diversas vezes esse comportamento. $O$ padrasto de Larissa, entretanto, declarava não saber o que fazer diante dessas "crises" da menina. Dizia que esperava que ela se acalmasse e que, em seguida, conversava com ela sobre não ser necessário fazer aquilo, que não se pode fazer tudo na hora em que se quer e que, às vezes, chamava a tia dela, que morava próximo à casa deles, para conversar com ela, pois, com essa tia (irmã da mãe), ela ficava mais calma.

Sabrina nos conta que, quando engravidou de Larissa, o pai dela, seu ex-marido, não morava mais com ela. A avó materna foi quem ajudou a cuidar da menina, porque a mãe trabalhava muito. Ela nos conta que, durante a infância de Larissa, o pai dela a visitou em poucos momentos, mas que, atualmente, ela e o pai viam-se com mais freqüência. Em seguida, ressalta bastante o quanto é envolvida com o emprego, saindo de casa antes das 7 horas da manhã e retornando depois das 19 horas, associando a isso o fato de que, quando ela sai para trabalhar, a filha ainda está dormindo e que, quando ela chega, às vezes a filha já foi dormir. Da mesma maneira, também tinha pouco contato com o filho, já que o pai o deixava na creche pela manhã e o buscava no final da tarde.

Também nos relata que "desde sempre" Larissa se comportou assim. Quando o padrasto foi morar com elas, Larissa tinha quatro anos, mas, antes disso, segundo Sabrina, ela já ficava nervosa, quando era contrariada. No entanto, quando passaram a morar todos juntos, a situação piorou: a mãe achava que na "cabecinha dela aquele lugar deveria ser ocupado pelo pai". Ela diz que, embora nunca o pai tenha morado junto com ela e a fiIha, para Larissa era como se um dia isso houvesse acontecido e, por isso, aguardava seu retorno.

O casal não sabia dizer o porquê de Larissa agir dessa forma, não tinha hipótese sobre isso, embora a mãe associasse com o fato de não ter cuidado muito dela quando pequena.

Após esse período inicial, nossas hipóteses foram se encaminhando para a falta que a menina sentia de ser cuidada, principalmente pela mãe, e que buscava, de uma maneira inadequada, alertá-la disso. Para Winnicott (1971), a criança ou o adolescente que apresenta comportamentos antisociais está revelando, por meio desse sintoma, o direito que sente de resgatar o amor da mãe, em algum momento perdido. Portanto, segundo esse autor, tal sintoma está diretamente ligado à realidade psíquica da criança, e não simplesmente ao seu comportamento.

Ao longo do atendimento, houve, por parte da mãe, uma postura cada vez mais rígida, tanto na forma de falar quanto na maneira de lidar com a filha. Levantamos a hipótese dessa mãe estabelecer um vínculo pouco afetivo com sua filha, em função das dificuldades vivenciadas por ela, desde a infância, que poderiam remontar ao seu relacionamento com sua 
própria mãe, e que, portanto, poderia estar "projetando" na menina repetições de situações de difícil elaboração por parte dela, uma vez que marcas profundas a poderiam estar afastando da menina e de um contato mais íntimo com a área afetivo-emocional. Em nenhum momento dessas entrevistas a mãe aponta características positivas da filha ou procura compreender o comportamento dessa com outro olhar que não o de condenamento: "Eu não sou muito de ficar paparicando criança, sabe? Pegar no colo, nada. Eu chego em casa, arrumo minhas coisas e vou dormir. Tem dias que falo 'Oi', tem dias que eu não falo." Ela diz ainda que não sabe a hora em que as crianças vão dormir, porque, normalmente, o marido fica com eles, assistindo televisão. Continua o relato salientando que não consegue entender porque Larissa é assim nervosa, se não tem preocupação com nada.

Em relação ao que acha que pode estar faltando para Larissa, ela remete à ausência de autoridade; diz concordar com a professora, que falou que a menina precisava de limite.

Após essa etapa inicial, optamos por realizar algumas entrevistas com Larissa. No primeiro contato terapêutico é surpreendente a criança que se apresenta. Essa tinha um sorriso doce e profundo, parecia meiga e envergonhada. Aceitou o convite para entrar na sala e foi começando a contar sua versão dos fatos, já relatados pela mãe e padrasto anteriormente.

Larissa relata que realmente fica muito nervosa, às vezes, sente vontade de se matar e de matar os outros, já que ninguém gosta dela. Conta, com uma voz baixa e terna, que sua mãe só batia e brigava com ela, que quando seu irmão fazia qualquer bagunça a culpa era sempre dela. Sobre a escola, afirmou que sua professora gritava muito o tempo todo e que por isso ficava com dor de cabeça. Relata, também, que preferia estar numa outra escola, onde o primo estudava, porque, caso alguém fosse bater nela, ele a defenderia. Larissa ainda nos aponta que não gosta de ver a mãe chorar. Aqui, já podemos perceber o quanto essa menina se sentia mal e desconfortável na dinâmica familiar, bem como se sentia culpada pelo sofrimento da mãe, que a colocava no lugar de culpada. Ela aceita continuar com os encontros, muito satisfeita.

Ao longo desses encontros iniciais, pudemos compreender o quanto essa menina sentia "falta de ser cuidada por sua mãe" e o quanto estava regredida emocionalmente. Percebemos que a mensagem que Larissa recebia de sua mãe era a de que crescesse rápido, ignorando seu lado infantil, e qualquer espaço que Larissa reservasse para a brincadeira, para a diversão, não era compartilhado por sua mãe. Não havia qualquer tipo de continência, dessa última, para as questões relacionadas à infância da menina. Larissa possuía uma auto-imagem muito denegrida, dizendo-se "louca", "azarada", além de se sentir muito culpada por qualquer fato que atingisse sua mãe. Ao mesmo tempo, também vamos percebendo, em seu discurso, uma realidade bastante idealizada, principalmente quando se referia ao pai, que ela visitava aos domingos. Conversamos, então, com ela sobre a 
possibilidade de incluirmos sua mãe nas sessões, pois julgamos que era o vínculo entre as duas que deveria ser tratado, e não apenas Larissa. Para isso propusemos um setting propício ao brincar, de acordo com Winnicott (1971). Como os sintomas (ou queixas) apresentados pela menina estavam intrinsecamente relacionados à dinâmica familiar estabelecida e, fundamentalmente, ao que dizia respeito à função materna e como vinha sendo exercida, optamos pela terapia familiar como a melhor estratégia clínica.

Pudemos observar, no decorrer do tratamento, que os apontamentos que a mãe fazia para a filha eram duros e sérios, apesar de estarem brincando. Entretanto, era nítida a alegria da menina em ver sua mãe aparentemente disponível para "brincar" com ela. Ela jogava damas com a filha como se estivesse jogando com um adulto, e exigia que a menina se concentrasse o suficiente, porque "não iria adiantar chorar depois". Esse comportamento da mãe nos fez pensar que ela adotava uma postura "de igual para igual" em relação à menina, disputando com ela como se fosse uma outra criança, incapaz de dar continência à filha e de se colocar na relação enquanto mãe. Percebemos, inclusive, o quanto essa mãe também não se sentia cuidada e, talvez, por isso, era incapaz de cuidar.

Num determinado momento desse tratamento, é dito à mãe o quanto se percebia que o comportamento da menina se devia a algo "faltante" no vínculo das duas. Sabrina concorda e diz achar que realmente não dá muita atenção e carinho aos filhos, que deveria cuidar mais deles, porém, não o fazia porque trabalhava muito.

Aos poucos, foi sendo apontado a ela o quanto nos parecia que Larissa estava precisando muito desse cuidado, dando elementos para a mãe pensar no comportamento da filha sob essa ótica. Através do cuidado de si, que Sabrina também recebeu por meio do vínculo com a terapeuta, que, transferencialmente, sentia-se mãe das duas, foi possível orientá-la no sentido de procurar se colocar mais próxima, na relação com a menina, tendo mais paciência (holding) com ela, estando atenta às características boas que Larissa possuía, valorizando o que a filha procurava constantemente oferecer a ela. Para Larissa, procurou-se mostrar o quanto aquela situação não era por culpa dela, reforçando seus aspectos positivos e a própria dificuldade da mãe em cuidar dela. Concomitantemente, a mãe foi apresentando os motivos intrínsecos à sua dificuldade em poder exercer uma maternagem suficientemente boa (Winnicott, 1956/2000).

\section{Transmissão psíquica transgeracional e maternagem}

Nossa hipótese sobre a dificuldade de Sabrina em exercer a maternagem estava atrelada a uma questão dela, construída em sua história de vida, que ela própria relatou, com seu jeito bastante simples: 
Eu não tive infância; meu pai ficou doente e com onze anos eu tive que ir trabalhar... Alguém tinha que botar dinheiro em casa para comer, nós éramos em cinco filhose eu era a mais velha, minha boneca era a enxada. A gente trabalhava na roça mesmo, em caminhão de bóia-fria, eu nem sei se você sabe o que é isso.

Portanto, demonstra ter vivido muito rapidamente sua infância, sendo "obrigada" a crescer precocemente, sem ter podido desfrutar da maternagem com sua mãe, o que a impediu de exercer essa função com Larissa e de entender e compartilhar do universo infantil da filha, cuja realidade vivida é diversa da que foi a sua no passado; ou seja, Larissa não necessita crescer rapidamente, como sua mãe precisou, podendo aproveitar esse período de maneira mais saudável.

A força da herança transmitida por duas gerações (mãe e avó) ${ }^{6}$ impede que se estabeleça uma nova forma de se vincular no presente, entre Larissa e sua mãe, gerando conflitos e sintomas naquela que se coloca como sujeito independente, nesse processo de transmissão psíquica transgeracional (Correa, 2000a).

Consideramos importante que a terapia psicanalítica familiar pudesse se debruçar sobre essas questões e possibilitar que esse material, que se encontrava em "suspenso", pudesse ser metabolizado e pensado, proporcionando novas formas de se vincular nessa família e propiciando saúde psíquica a essa menina, na medida em que ela pudesse ter a chance de um processo de construção da subjetividade feminina "transformador", novo e criativo, a partir das suas próprias vivências, como autora de sua história e não apenas como coadjuvante de um script pré-determinado por suas antecessoras.

\section{Considerações finais}

É no espaço da terapia familiar que começa a ocorrer a transformação no vínculo mãe/filha, com uma proximidade afetiva de natureza diferente entre ambas, resultando na eliminação das queixas ou sintomas de agressividade da menina. Sabrina esforça-se por entender as necessidades da filha, estabelece mudanças na rotina doméstica, torna-se mais presente na vida dos filhos, permitindo que aproveitem mais a etapa infantil. Mostrase mais calma, com maior disposição para brincar com as crianças, embora, algumas vezes ainda retorne à posição anterior, sendo e exigindo um certo "endurecimento" da menina, como defesa frente às dificuldades da vida. Larissa, por sua vez, nunca mais falou em se matar; parece mais feliz, porém, ainda é forte o ciúme que nutre pelo irmão e o desejo de ser aceita pelo pai. 
Na relação transferencial, Sabrina disputa com a filha a atenção da terapeuta, tentando reviver, na situação terapêutica, o que não teve na família de origem: acolhimento e continência. E é nessa experiência vincular que vem encontrando modelos para construir, dentro de si, uma nova subjetividade envolvendo o papel de mulher e mãe.

Embora a situação terapêutica seja permeada de "altos e baixos", não podemos negar o forte interesse de Sabrina pela terapia e sua disponibilidade em melhorar a relação com a filha. No decorrer do processo, ela acabou optando por deixar o emprego para estar mais próxima da menina; todavia, ainda não podemos afirmar que se tornou uma mãe "suficientemente boa",completamente compreensiva em relação a todas as questões da filha e inteiramente disponível a ela.

A demonstração de afeto entre as duas ainda não se dá espontaneamente, elas têm dificuldades de expressar em palavras o que sentem uma para a outra, ainda é mais fácil a mobilização pelo lado do conflito; contudo, não podemos, igualmente, negar que Sabrina está muito diferente de como chegou à terapia. Atualmente, ela é capaz de dimensionar a infância dentro de uma nova ótica, do "brincar",e não no sentido de impor precocemente a "dureza" da vida adulta aos filhos, como uma repetição do que foi a sua infância e a de seus antepassados.

Concluindo, foi preciso, enquanto terapeutas, deixarmos de lado os valores, estigmas e as pré-concepções do que deveria ser uma mãe "suficientemente boa", ou as expectativas frente às mudanças em Sabrina, para conseguirmos perceber o quanto ela, segundo suas condições psíquicas, derivadas do legado da transmissão psíquica na sua história de vida, estava procurando e conseguindo oferecer à sua filha, dentro de suas possibilidades. Com isso, propiciamos e ela e a nós próprias, enquanto profissionais sempre em desenvolvimento, a possibilidade de observar a força transformadora do vínculo terapêutico, que permite a elaboração desse "fardo" geracional, promovendo o surgimento de uma subjetividade nova.

\section{Transgenerational psychic transmission and construction of subjectivity: report of a psychoanalytic linkage psychotherapy}

Abstract: This article has as an objective to reflect concerning the concept of psychic transmission among generations, specifically of one modality - the transgenerational psychic transmission - and its influence on the creation of the individual subjectivities and of the family links, being emphasized mainly the link of mother-daughter as generator of symptoms in the child and familiar conflicts, through a clinical report of a psychoanalytic linkage psychotherapy, according to the references of Eiguer (2006) and Berenstein and Puget $(1997,2005)$. The presentation 
of the clinical case allows discussing the relationship between the transgenerational psychic transmission and the establishment of the "primary maternal preoccupation" as well as the results obtained along the whole psychotherapeutic process. The purpose of this family therapeutic space is to offer transformations join to the generational legacy promoting the appearance of a new subjectivity generating of life.

Keywords: Psychic transmission between generations. Subjectivity. Psychoanalytic psychotherapy. Link.

\section{Transmission psychiquetransgénérationnelleetconstruction dela subjectivité: récit d'une psychothérapie psychanalitique du lien}

Résumé: Le présent article a comme objectif réfléchir sur le concept de transmission psychique entre des generations, spécifiquement d'une modalité - la transmission psychique transgénérationnelle - et son influence dans la construction des subjectivités individuelles et des liens familiers. Ici l'on souligne le lien mère-fille comme générateur de symptômes chez l'enfant et de conflits dans le contexte familier, à travers un récit clinique d'une psychothérapie psychanalitique du lien, selon les référentiels d'Eiguer (2006) et de Berenstein et Puget $(1997,2005)$. La présentation du cas clinique permet de discuter, encore, le rapport entre la transmission psychique transgénérationnelle et l'établissement du « maternage », ainsi que les résultats obtenus au long de tout le processus psychothérapique. Le but de cet espace thérapeutique familier est de rendre propice des transformations face au legs générationnel, en promouvant le surgissement d'une subjectivité nouvelle, stimulatrice de vie.

Mots-clés:Transmission psychique transgénérationnelle.Subjectivité.Psychothérapie psychanalitique. Lien.

\section{Transmisión psíquica transgeneracional y construcción de la subjetividad: relato de una psicoterapia psicanalítica vincular}

Resumen: El presente artículo tiene como objetivo reflejar sobre el concepto de la transmisión psíquica entre las generaciones, específicamente de una modalidad - la transmisión psíquica transgeneracional - y su influencia en la construcción de las subjetividades y de los vínculos familiares, destacando el vínculo madre-hija como generador de síntomas en el niño y los conflictos en el aspecto familiar; 
por medio de un relato clínico de una psicoterapia psicanalítica vincular, según las referenciais de Eiguer (2006) y Berenstein y Puget $(1997,2005)$. La presentación del caso clínico permite discutir aún la relación entre la transmisión psíquica transgeneracional y el establecimiento del "maternaje", así como los resultados obtenidos por medio del proceso psicoterápico. El propósito de este espacio terapéutico familiar está en proporcionar las transformaciones delante la herencia generacional, promoviendo el surgimiento de una nueva subjetividad impulsionadora de la vida.

Palabras clave: Transmisión psíquica entre las generaciones. Subjetividad. Psicoterapia psicanalítica.Vínculo.

\section{Referências}

Berenstein, I., \& Puget, J. (1993). Psicanálise do casal. Porto Alegre: Artes Médicas.

Berenstein, I., \& Puget, J. (1997). Lo vincular. Clínica y técnica psicoanalítica. Buenos Aires: Paidós.

Berenstein, I., \& Puget, J. (2004). Noción de vínculo. Recuperado em 19 de outubro de 2004, de www. apdeba. org (Classe No.2, Texto disponibilizado pela Internet referente ao curso de Psicoanálisis de Família, Nível I, promovido pelo Campus Virtual da APDBA, Associação Psicanalítica de Buenos Aires)

Berenstein, I., \& Puget, J. (2005). A família na situação. Material clínico. Recuperado em 24 de agosto de 2005, de www. apdeba. org (Classe No.2, Texto disponibilizado pela Internet referente ao curso de Psicoanálisis de Família, Nível II, promovido pelo Campus Virtual da APDBA, Associação Psicanalítica de Buenos Aires)

Bleger, J. (1972). Temas de psicologia. Buenos Aires: Nueva Visión.

Bion, W. (1970). Experiências com grupos. Rio de Janeiro: Imago.

Correa, O. B. R. (Org.). (2000a). Os avatares da transmissão psíquica geracional. São Paulo: Escuta.

Correa, O. B. R. (Org.). (2000b). O legado familiar: a tecelagem grupal da transmissão psíquica. Rio de Janeiro: Contra Capa.

Eiguer, A. (1998). A transmissão do psiquismo entre gerações: enfoque em terapia familiar psicanalítica. São Paulo: Unimarco Editora.

Eiguer, A. (2006). Por um psicoanálisis familiar recreativo. Psicoanálisis e intersubjetividad: familia, pareja, grupos e instituciones, (1). Recuperado em 11 de agosto de 2006, de www.intersubjetividad.com.ar

Féres-Carneiro, T., \& Magalhães, A. S. (2005). Conquistando a herança: sobre o papel da transmissão psíquica familiar no processo de subjetivação. In T. Féres-Carneiro (Org), Família e casal: efeitos da contemporaneidade (pp. 24-32). Rio de Janeiro: Ed. PUC-Rio. 
Freud, S. (1980). Psicologia de grupo e a análise do ego. In S. Freud, Edição standard brasileira das obras psicológicas completas de Sigmund Freud (J. Salomão, trad., Vol. 18, pp. 89-179). Rio de Janeiro: Imago. (Trabalho original publicado em 1921)

Gomes, P. B., \& Porchat, I. (2006). Psicoterapia do casal. São Paulo: Casa do Psicólogo.

Granjon, E. (2000). A elaboração do tempo genealógico no espaço do tratamento da terapia familiar psicanalítica. In O. B. R. Correa (Org.), Os avatares da transmissão psíquica geracional (pp. 17-43). São Paulo: Escuta.

Jaroslavsky, E. A. (2006). El modelo vincular franco-argentino contemporâneo. Psicoanálisis e intersubjetividad: familia, pareja, grupos e instituciones, (1). Recuperado em 11 de agosto de 2006, de www.intersubjetividad.com.ar

Kaës, R. (1997). O grupo e o sujeito do grupo: elementos para uma teoria psicanalítica do grupo. São Paulo: Casa do Psicólogo.

Kaës, R. (1998). Os dispositivos psicanalíticos e as incidências da geração. In A. Eiguer, A transmissão do psiquismo entre gerações: enfoque em terapia familiar psicanlítica (pp. 5-19). São Paulo: Unimarco Editora.

Kaës, R. (Org.). (2001). Transmissão da vida psíquica entre gerações. São Paulo: Casa do Psicólogo.

Pichon-Rivière, E. (1983). Processo grupal. São Paulo: Martins Fontes.

Trachtenberg, A. R. C., Kopittke, C. C., Pereira, D. Z. T., Chem, V. D. M., \& Mello, V. M. H. P. (2005). Transgeracionalidade: de escravo a herdeiro: um destino entre gerações. São Paulo: Casa do Psicólogo.

Winnicott, D. W. (1971). O brincar e a realidade (J. O. A. Abreu \& V. Nobre, trads.). Rio de Janeiro: Imago.

Winnicott, D. W. (2000). A preocupação materna primária. In D. W. Winnicott, Da pediatria à psicanálise (D. Bogomoletz, trad., pp. 399-405). Rio de Janeiro: Imago. (Trabalho original publicado em 1956) 
Isabel Cristina Gomes, Professora Associada do Departamento de Psicologia Clínica do IPUSP, Endereço para correspondência Av. Prof. Mello Moraes, 1721 - Bloco F, Cidade Universitária - Butantã, CEP 05508-030 - São Paulo, SP, Fone: (11) 3091- 4910, Endereço eletrônico: isagomes@ajato.com.br

Sandra Aparecida S. Zanetti, Mestranda do Programa de Pós-Graduação em Psicologia Clínica do IPUSP, Bolsista FAPESP, Endereço para correspondência: R. Vicente Fernandes Pinto, 159 - apto 41-B - Água Funda, CEP 04156-000, Fone: (11) 5058- 1912. Endereço eletrônico: sandra.zanetti@gmail.com

Recebido em: 6/10/2007

Aceito em: 10/03/2008 